\title{
Budget impact of introducing tofacitinib to the public hospital formulary in Hong Kong, 2017-2021
}

\author{
X Li, Swathi Pathadka, Kenneth K Man, lan CK Wong, Esther WY Chan *
}

\section{A B S T R A C T}

Introduction: As the first approved oral kinase inhibitor, tofacitinib is effective and well-tolerated, but more expensive than conventional treatments for uncontrolled rheumatoid arthritis. Public formulary listing typically exerts a positive impact on the uptake of new drugs. We aimed to assess the budgetary impact of introducing tofacitinib into the Hospital Authority Drug Formulary as a fully subsidised drug in Hong Kong.

Methods: We applied a population-based budget impact model to trace the number of eligible patients receiving biologics or tofacitinib treatment, then estimated the 5-year healthcare expenditure on rheumatoid arthritis treatments, with or without tofacitinib (2017-2021). We used linear regression to estimate the number of target patients and compound annual growth rate to estimate market share. Competing treatments included abatacept, adalimumab, certolizumab pegol, etanercept, golimumab, infliximab, and tofacitinib. Retail price was used for drug costs, valued in Hong Kong dollars (HK\$) in 2017 and discounted at 4\% per year.

This article was published on 29 May 2019 at www.hkmj.org.
Results: The annual treatment cost of tofacitinib was HK\$74214 per patient, and the costs of biologics ranged from HK\$64350 to HK\$115700. Without tofacitinib, the annual government health expenditures for rheumatoid arthritis treatment were estimated to increase from HK\$147.9 million (2017) to HK\$190.6 million (2021). The introduction of tofacitinib to the formulary would reduce healthcare expenditures by $17.3 \%$ to $20.3 \%$ per year, with cumulative savings of HK\$192.8 million; this change was estimated to provide consistent savings (HK\$66.4 million to HK\$196.8 million) in all tested scenarios.

Conclusion: Introduction of tofacitinib to the formulary will provide 5-year savings, given the current drug price and patient volume.

\section{${ }^{1} \mathrm{X} \mathrm{Li}, \mathrm{PhD}$ \\ ${ }^{1} \mathrm{~S}$ Pathadka, PharmD \\ ${ }^{2}$ KK Man, BSc, MPH \\ 1,2 ICK Wong, PhD \\ ${ }^{1}$ EWY Chan *, PhD}

Hong Kong Med J 2019;25:201-8

https://doi.org/10.12809/hkmj187673

\section{Department of Pharmacology and Pharmacy, The University of Hong Kong, Pokfulam, Hong Kong \\ 2 School of Pharmacy, University College London, London, United Kingdom}

* Corresponding author: ewchan@hku.hk

\section{New knowledge added by this study}

- Government healthcare expenditures for treatment of rheumatoid arthritis were estimated to be lowered by approximately $20 \%$ upon the introduction of tofacitinib.

- The cost-saving impact of introducing tofacitinib to the Hospital Authority Drug Formulary is determined by interactions between drug prices and market shares of novel disease-modifying anti-rheumatic drugs (DMARDs).

Implications for clinical practice or policy

- Based on current drug prices and patient volume, introduction of tofacitinib to the Hospital Authority Drug Formulary will lower healthcare expenditures for at least 5 years.

- Tofacitinib will offer an orally administered option for patients who showed poor response to initial therapy and will intensify market competition for DMARDs.

\section{Introduction}

Rheumatoid arthritis (RA) is a chronic connective tissue autoimmune disorder that leads to considerable functional disability, reduced quality of life, and loss of earning capacity ${ }^{1}$ Conventional synthetic disease-modifying anti-rheumatic drugs (csDMARDs), such as methotrexate, have long been regarded as the standard of care for RA and are widely used in newly diagnosed patients to slow disease progression, control disease manifestations, and achieve remission. ${ }^{2,3}$ However, csDMARDs exhibit relatively slow onset of action and require close monitoring due to the potential for adverse events, especially in patients with chronic co-morbidities.,4 For patients who exhibit poor prognostic factors with moderate to high disease activity after initial 


\section{托法替尼納入香港公立醫院藥物名冊的預算 影響分析 \\ 李雪、Swathi Pathadka、文鏡彰、黃志基、陳慧賢}

引言：作為首種被認可的口服激酶抑製劑, 托法替尼已被證實對治療 難治性類風濕性關節炎比傳統療法更安全有效, 但價格較昂貴, 所以 尚未被廣泛使用。由於新藥被納入公立醫院藥物名冊後, 政府全面資 助其費用, 故此常常有助推動提高新藥的使用率。本研究旨在評估將 托法替尼納入醫管局藥物名冊後對香港醫療藥物財政預算的影響。

方法：本研究根據香港人口電子數據庫資料而採用預算影響分析模 型, 追踪符合資格使用新型療法（生物製劑或托法替尼）的類風濕 性關節炎的病人數目, 繼而估計五年 (2017-2021) 內相關的醫療支 出, 比較托法替尼納入藥物名冊與否對財政預算的影響。我們採用線 性回歸來估計目標患者的數目和不同藥物市場份額的變化。可供市場 選擇的療法包括阿貝西普、阿達木單抗、賽妥珠單抗、依那西普、戈 利木單抗、英夫利昔單抗和托法替尼。藥物成本以2017年市場零售價 格計算（以港元計算）, 貼現率為每年 $4 \%$ 。

結果：托法替尼的每年治療費用為每位病人74214港元, 生物製劑 的費用為64350至115700港元。若不納入托法替尼, 用於類風濕性 關節炎的政府醫療支出將從每年147900 000港元（2017年）增至 190600000 港元（2021年）。納入托法替尼使相關醫療支出每年減 少 $17.3 \%$ 至 $20.3 \%$, 累計節省 192800000 港元。研究分析結果顯示, 在不同市場佔有率和藥物停用率的情況下, 納入托法替尼能夠在五年 間持續節省66400000港元至196800000港元。

結論 : 根據現時藥品價格和病人數量, 將托法替尼納入香港公立醫院 藥物名冊能夠節省五年內的相關醫療支出。 therapy with csDMARDs, novel biologic DMARDs (eg, infliximab, adalimumab, certolizumab pegol, or golimumab) or targeted synthetic, small-molecule DMARDs (eg, tofacitinib) are recommended for use in combination with csDMARDs, or as monotherapy. ${ }^{2,3,5}$

Tofacitinib is a small synthetic molecule Janus kinase inhibitor which modulates leukocyte recruitment, activation, and effector cell function at sites of inflammation. It is the first orally bioavailable therapeutic agent to improve clinical remission in patients with RA. ${ }^{6}$ The safety and efficacy of tofacitinib, relative to those of csDMARDs, have been reported in recent landmark trials and observational studies. Tofacitinib monotherapy was superior to methotrexate for reduction of RA symptoms and inhibition of the progression of structural joint damage in patients who had not previously received methotrexate or therapeutic doses of methotrexate. ${ }^{7}$ In patients with inadequate responses to methotrexate, tofacitinib was noninferior to adalimumab for symptom control when used as a combination therapy with methotrexate. ${ }^{8}$ However, the increased risk of adverse events associated with tofacitinib, including infections (eg, herpes zoster and tuberculosis) and malignancy, is a major limitation that requires long-term surveillance and careful prescribing practices. ${ }^{7,8}$

Similar to biologic DMARDs, tofacitinib is more expensive than csDMARDs (eg, methotrexate $\$ 1$ versus tofacitinib $\$ 66$ per tablet in the $\mathrm{US}^{9}$ ). Several studies have supported the cost-effectiveness of tofacitinib. When used as an alternative first-line treatment to csDMARD, tofacitinib was found to be cost-effective in the South Korean population due to its ability to significantly improve patients' quality of life. ${ }^{10}$ When used in combination with a csDMARD, a study in the US showed that tofacitinib was highly cost-effective in patients with severe RA, relative to combinations of most biologics with csDMARD. ${ }^{11}$ In a recent modelling study, tofacitinib was also found to be cost-saving as a second-line therapy following methotrexate failure and as a third-line therapy following the failure of a biologic therapy. ${ }^{12}$

Treatment decisions for patients with uncontrolled RA are increasingly complex because there are no direct head-to-head comparisons among novel DMARDs from landmark trials, and there are limited long-term data describing medication safety and compliance. Selection of biologic DMARDs or tofacitinib is largely dependent on multiple clinical and socio-economic factors, including disease activity, progression of structural damage, and co-morbidities within a particular patient, as well as their preferences for route of administration and dosing frequency, and the regulatory and cost barriers to drug access. ${ }^{13}$

Tofacitinib was approved in Hong Kong as a prescription-only drug in $2014 .{ }^{14}$ At the time of writing, tofacitinib is listed as a self-financed item without safety net in the public hospital formulary; thus, the cost of tofacitinib is entirely out-of-pocket for patients. ${ }^{15}$ The impact of funding tofacitinib in the public healthcare system remains unknown. In the present study, we assessed the budgetary impact of introducing tofacitinib into the Drug Formulary of the Hospital Authority-the statutory body that manages Hong Kong's public hospital services. The objective of this study was to provide guidance for drug listing decisions from a public institutional perspective.

\section{Methods}

\section{Target population}

The target population comprised adults with RA who showed inadequate response to initial cSDMARD monotherapy and were recommended for treatment with novel DMARDs. ${ }^{2,5}$ Adult patients who had been treated with novel DMARDs, during the period from 1 January 2009 to 31 December 2015, were identified from the Clinical Data Analysis and Reporting System (CDARS) of Hong Kong (a territory-wide electronic health record). Developed by the Hospital Authority, a statutory body that 
manages all public hospitals and provides health service to all Hong Kong residents (over 7 million), ${ }^{16}$ CDARS is recognised as a unique population-based electronic health record in Hong Kong that enables publication of an increasing number of high-quality studies. ${ }^{17-21}$ A detailed description of CDARS can be found elsewhere. ${ }^{22-24}$ In this study, retrieved data from the electronic patient records included demographics, date of registered death, date of hospital admission and discharge, drug dispensing records and diagnoses. Patient records from CDARS are de-identified and linked with unique reference keys to protect patient privacy and facilitate data retrieval. Based on the eligible patients identified from CDARS, the number of patients on novel DMARDs was calculated annually between the year of 2009 and 2015 and projected for the years from 2017 to 2021 assuming a linear trend of increasing in patients receiving novel DMARDs (online supplementary Appendix 1).

\section{Budget impact model}

We developed a population-based budget impact model to trace the number of patients with RA on novel DMARDs and assess changes in healthcare expenditures with respect to RA treatments (Fig 1). The model used a cohort of patients diagnosed with RA who showed inadequate responses to initial DMARD therapy. Without the introduction of tofacitinib, patients were assumed to use one of the biologic DMARDs (monotherapy or combination therapy with a csDMARD), according to its corresponding market share. The introduction of tofacitinib provided an additional option to patients newly placed on novel DMARDs, with treatment choices determined by projected market share. We assumed that the annual retention rate of biologics was $100 \%$, whereas that of tofacitinib was $80 \%$, in accordance with landmark trial results. ${ }^{7}$ Dropout patients were assumed to switch to one of the biologics, according to its corresponding market share in the same year. We also assumed that the safety and efficacy profiles of biologics and tofacitinib were equivalent, based on a recent Cochrane review that assessed novel DMARDs compared to placebo or standard care, ${ }^{25}$ and based on a head-to-head comparison between tofacitinib and adalimumab. ${ }^{8}$ The assumptions of the projection model are summarised in online supplementary Appendix 2.

The analysis was conducted from the public institutional perspective of Hong Kong, and direct medical costs were calculated. The numbers of patients on each treatment and overall medication costs were calculated on a yearly basis, and results were cumulative over a period of 5 years (20172021). Monetary value was expressed in Hong Kong dollars $(\mathrm{HK} \$)$ in 2017 , discounted at $4 \%$ per year. ${ }^{26,27}$ The study outcome was the difference in healthcare

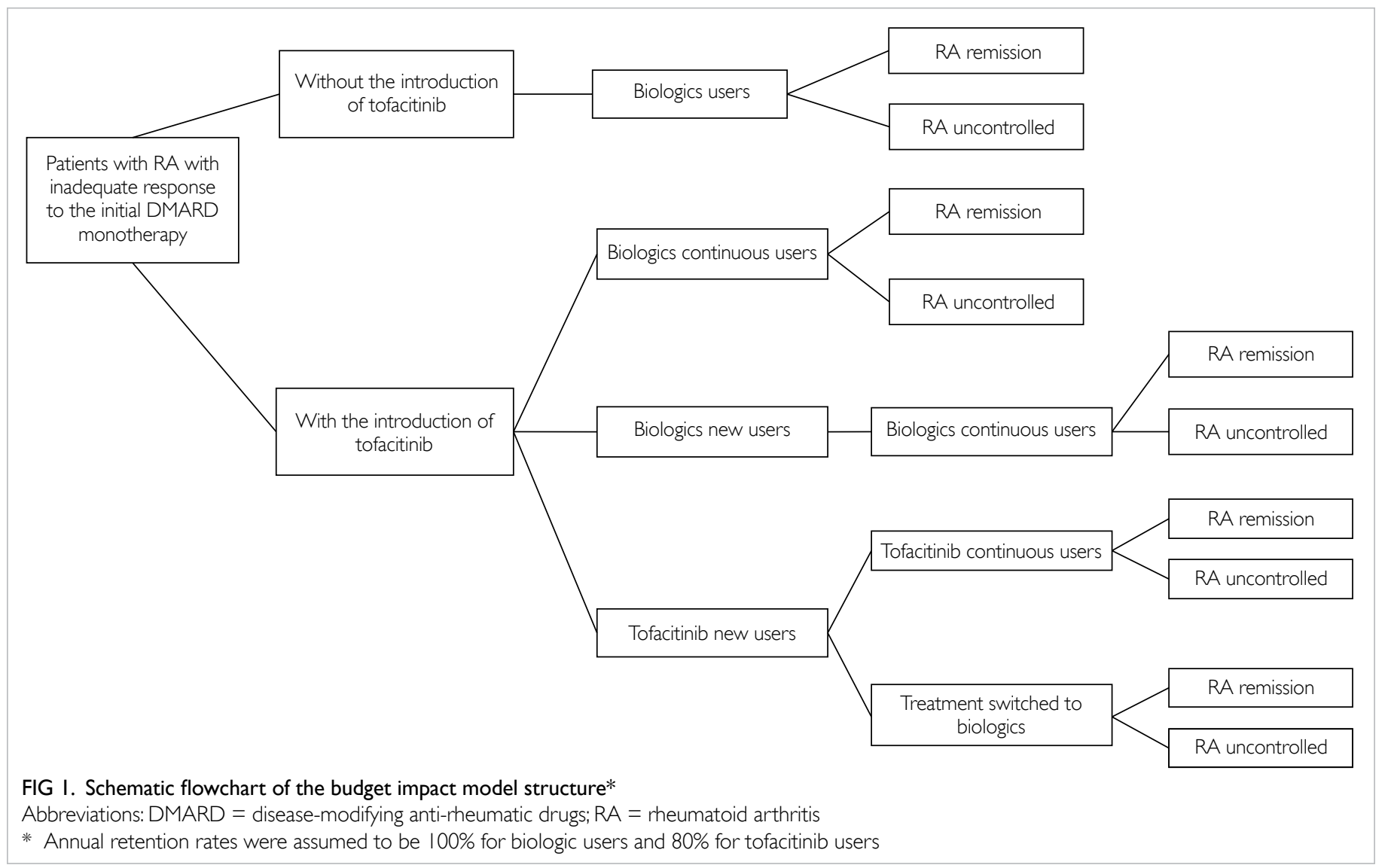


TABLE I. Dosage regimen and unit costs for the treatment options

\begin{tabular}{|c|c|c|c|c|}
\hline Treatment & Dosage & Route & $\begin{array}{c}\text { Unit cost } \\
\text { (HK\$) }\end{array}$ & $\begin{array}{c}\text { Annual cost } \\
\text { (HK\$/patient) }\end{array}$ \\
\hline Abatacept & $500 \mathrm{mg}(<60 \mathrm{~kg})$ or $750 \mathrm{mg}(60-100 \mathrm{~kg})$, every 4 weeks & Intravenous & 7100 & 92300 \\
\hline Adalimumab & 40 mg, every 2 weeks & Subcutaneous & 4226 & 109876 \\
\hline Certolizumab pegol & 200 mg, every 2 weeks or 400 mg, every 4 weeks & Subcutaneous & 5757 & 74841 \\
\hline Etanercept & 50 mg, weekly & Subcutaneous & 1875 & 97500 \\
\hline Golimumab & 50 mg, monthly & Subcutaneous & 7200 & 93600 \\
\hline Infliximab & Initial $3 \mathrm{mg} / \mathrm{kg}$, up to $10 \mathrm{mg} / \mathrm{kg}$, every 8 weeks & Intravenous & 4950 & 64350 \\
\hline Tocilizumab & Initial $4 \mathrm{mg} / \mathrm{kg}$, up to $8 \mathrm{mg} / \mathrm{kg}$, monthly & Intravenous & $\begin{array}{l}1780 \\
4450 \\
8900\end{array}$ & $\begin{array}{r}23140 \\
57850 \\
115700\end{array}$ \\
\hline Tofacitinib & 5 mg, twice daily & Oral & 102 & 74214 \\
\hline
\end{tabular}

TABLE 2. Base-case and scenario analyses

\begin{tabular}{lcc}
\hline & $\begin{array}{c}\text { New users of novel } \\
\text { DMARDs who will choose } \\
\text { tofacitinib }\end{array}$ & $\begin{array}{c}\text { Annual dropout of } \\
\text { tofacitinib }\end{array}$ \\
\hline Base-case (worst scenario) & $33.3 \%$ & $20 \%$ \\
Scenario 2 & $50 \%$ & $20 \%$ \\
Scenario 3 & $100 \%$ & $20 \%$ \\
Scenario 4 (best scenario) & $100 \%$ & 0 \\
\hline
\end{tabular}

Abbreviation: DMARDs = disease-modifying anti-rheumatic drugs

expenditures with respect to RA treatment, with or without introducing tofacitinib into the formulary. There was no pre-defined threshold for a favourable budget impact.

\section{Competing alternatives and market shares}

Treatment options were assumed to include biologics (eg, abatacept, adalimumab, certolizumab pegol, etanercept, golimumab, infliximab, and tocilizumab) and tofacitinib, using current recommendations for patients with inadequate responses to csDMARDs. Table 1 shows dosage regimens, per dose cost in local currency, and annual medication costs for each treatment. The number of patients on each treatment was determined by the corresponding market share of the treatment and the total number of eligible patients in the same year. Based on the number of biologics that were prescribed from 2013 to 2015 (as recorded in CDARS), the compound annual growth rate (CAGR) was estimated by following equation ${ }^{28}$ :

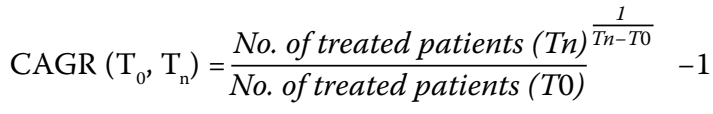

We assumed a constant CAGR for each biologic; the corresponding market share was projected yearly between 2017 and 2021 (online supplementary Appendix 3). The overall market share of novel DMARDs was assumed to be $100 \%$.

\section{Base-case and scenario analyses}

In the base-case analysis, we assumed that onethird of the eligible patients who were new users of novel DMARDs would be placed on tofacitinib in the first year. In accordance with the findings of the landmark trial, $20 \%$ of tofacitinib users were expected to drop out each year, due to adverse events. ${ }^{7}$ We assumed that the dropout patients would choose one of the biologics and that the efficacy and safety of tofacitinib and all biologics were equivalent; hence, the switch would only affect medication costs. Three scenario analyses were conducted to assess the impact of uncertainties on the base-case conclusion: specifically, uncertainties were considered in market share of tofacitinib and dropout of tofacitinib users (Table 2). The base-case scenario was regarded as the worst scenario for the uptake of tofacitinib (market share of 33.3\% among new novel DMARDs users and $20 \%$ annual dropout). In the other three scenarios, the first-year uptake of tofacitinib increased from $50 \%$ to $100 \%$, and the annual dropout rate ranged from $0 \%$ to $20 \%$. Scenario 4 was determined to be the best scenario, with the highest first-year uptake and 100\% retention over 5 years. We also tested the impact of discounting (0-4\%) on base-case results, as there are no health technology assessment guidelines with respect to the proper discount rate for Hong Kong.

Statistical Analysis System software (version 9.4, SAS Inc, Cary [NC], US) was used for data manipulation and analysis. Microsoft Excel (2003 for Windows; Microsoft Corp, Redmond [WA], US) was used to establish the budget impact model and generate corresponding plots.

\section{Ethics}

The study was designed and reported in accordance with the Consolidated Health Economic Evaluation Reporting Standards Statement. ${ }^{29}$ The study protocol in which CDARS was used to estimate the number of eligible patients was approved by the Hospital Authority Hong Kong West Cluster and The University of Hong Kong Institutional Review Board 
(UW14-602). Ethics approval for the budget impact analysis was waived, as it comprised a statistical modelling projection without patient contact.

\section{Results}

\section{Base-case analysis}

Between 2017 and 2021, the estimated number of eligible patients on novel DMARDs increased from 1466 to 2375 . Without introducing tofacitinib into the formulary, the annual government health expenditures for RA treatment were projected to increase from HK\$147.9 million (2017) to HK\$190.6 million (2021) [Fig 2a]. The increased expenditures were driven by increased patient volume and growth of the biologics market. Addition of tofacitinib to the formulary would reduce relevant healthcare expenditures by HK\$33.1 million to HK\$39.9 million annually ( $17.3 \%$ to $20.3 \%$ reduction) [Fig 2a]. Budgetary savings were expected, regardless of discount rates (Fig 2). Cumulative savings over the 5-year study period were projected to be HK\$192.8 million (discounted at 4\%) and $\mathrm{HK} \$ 208.8$ million (undiscounted), respectively.

\section{Scenario analyses}

Variations in the market share of tofacitinib were assessed in different test scenarios (Fig 3). The basecase scenario assumed the most conservative uptake of tofacitinib, comprising $4.4 \%$ to $10.7 \%$ of the overall novel DMARD market. With the assumption that half of the new users of novel DMARDs would choose tofacitinib, combined with the assumption of an annual dropout rate of $20 \%$ (Scenario 2), the market share of tofacitinib was expected to increase from $6.6 \%$ to $13.1 \%$ over the 5 -year study period. With the assumption that all new users of novel DMARDs would choose tofacitinib (Scenario 3), the market share was expected to increase from $13.2 \%$ to $32 \%$ over the 5 -year study period. In the best-case scenario (Scenario 4), 100\% uptake was assumed, combined with the assumption of an annual dropout rate of $0 \%$ among new users, the market share of tofacitinib was expected to increase linearly from $13.2 \%$ in 2017 to $46 \%$ in 2021.

The estimated annual health expenditures for RA treatments were positively correlated with the uptake of tofacitinib. In all tested scenarios, the introduction of tofacitinib to the public hospital formulary provided consistent savings, compared to the current situation where tofacitinib is selffinanced (Fig 4). Similar to the base-case scenario, the cumulative budget savings over the 5-year study period were estimated to be HK\$193.5 million and HK\$196.8 million for Scenarios 2 and 3. In the bestcase scenario with the highest uptake of tofacitinib, the total savings were reduced to HK\$66.4 million (Fig 4).

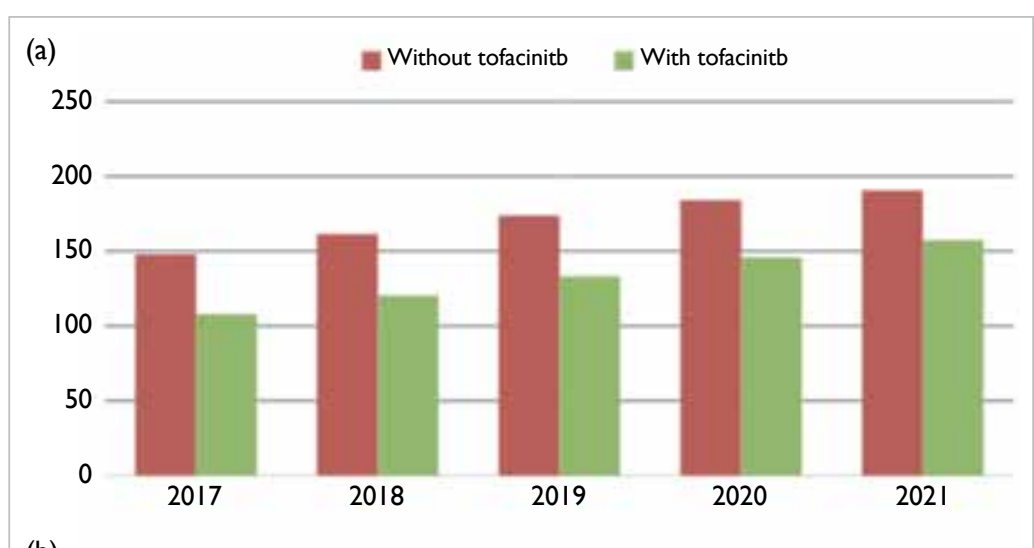

(b)

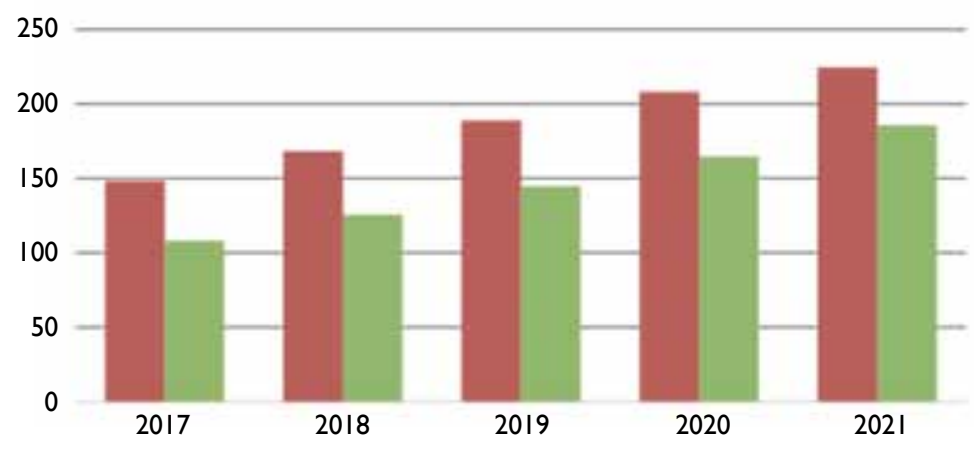

FIG 2. Projected healthcare expenditure on rheumatoid arthritis treatment, 20I72021 , showing (a) discounted costs and (b) undiscounted costs

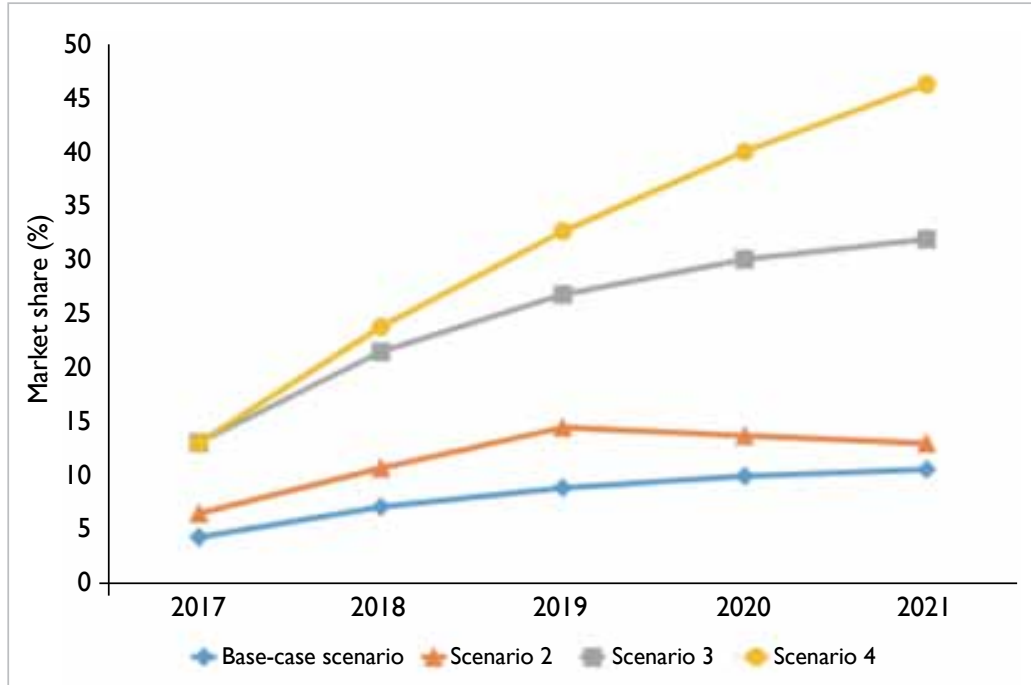

FIG 3. Projected market share of tofacitinib at different scenarios, 2017-202I

\section{Discussion}

In Hong Kong, patients with uncontrolled RA must pay HK\$20000 to HK\$100 000 per year out-of-pocket to receive novel DMARDs treatments that facilitate disease remission. In addition to the progressive loss of working ability associated with RA, the high cost of therapy poses an additional burden to 


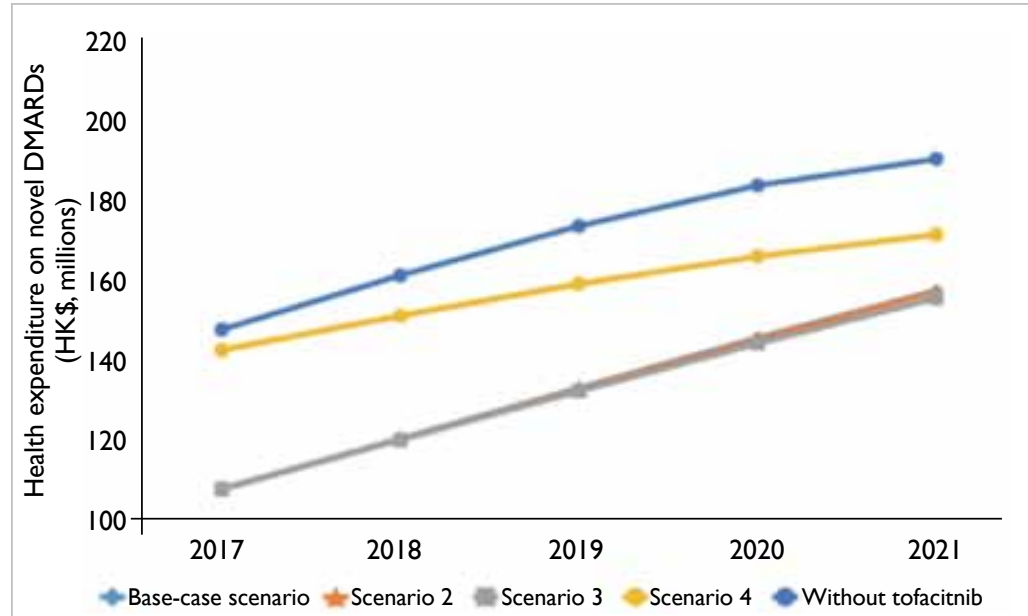

FIG 4. Budget savings with the introduction of tofacitinib at different scenarios Abbreviation: DMARDs = disease-modifying anti-rheumatic drugs

affected patients, their families, and society. ${ }^{30}$ In the present study, we attempted to provide guidance with respect to introduction of tofacitinib to the public hospital formulary by analysing the budgetary impact of this change. Drug listing and subsidy decisions rely on the principles of efficacy, safety, and cost-effectiveness; thus, they must consider a variety of factors, including clinical evidence and impact on healthcare costs. ${ }^{31}$ Budgetary impact is a key element of health economic evaluations that must be determined before formulary approval in many developed countries with established health technology assessments. ${ }^{32-34}$ Local and international health economists have suggested that systematic procedures and transparency are needed with respect to formulary decision-making in Hong Kong. ${ }^{35}$ Based on the current drug costs of novel DMARDs and the volume of patients who receive treatment in public hospitals in Hong Kong, our model projection suggests that the introduction of tofacitinib would provide savings over the 5-year study period.

In our analysis, governmental healthcare expenditures for RA treatments were lowered by approximately $20 \%$ upon the introduction of tofacitinib to the public hospital formulary. With the assumption that none of the novel DMARDs were discontinued or withdrawn from the market, the annual treatment costs of tofacitinib were lower than those of all biologics, except infliximab. This may explain the increased market share of tofacitinib, as well as the reduction in overall RA treatment costs. In clinical practice, both biologic DMARDs and tofacitinib are commonly used in combination with a csDMARD. ${ }^{2,3}$ In our analysis, we did not consider the cost of csDMARDs, as they are currently listed as fully subsided drugs in the formulary and are thus expected to have minimal impact on the cost of RA treatment, regardless of the addition of tofacitinib to the formulary.

The introduction of tofacitinib to the formulary will intensify market competition, which may improve the effectiveness of disease management ${ }^{36}$; moreover, this change will provide a more convenient orally administered option for patients who are reluctant to undergo subcutaneous or intravenous injections, and who are willing to switch from biologic DMARDs to an alternative therapy. ${ }^{37,38}$ Patient preferences regarding RA treatment may affect compliance, adherence, and quality of life. ${ }^{39,40}$ The route of administration significantly influences the decision between tofacitinib and biologics. ${ }^{41}$ Among all factors that impact patients' therapeutic preferences, the convenience of oral administration has been shown to exhibit the strongest influence. ${ }^{39}$ Thus, the oral route of administration for tofacitinib is likely to provide an advantage over the parenteral route of administration for biologics.

Given current evidence regarding the costeffectiveness of tofacitinib, broader utilisation of tofacitinib can be expected in the future if safety concerns are appropriately addressed. The underlying effector mechanism of tofacitinib comprises intracellular transduction inhibition, which carries the potential for interaction with the immune system; these factors may contribute to its associations with serious infections, herpes zoster, tuberculosis, gastrointestinal disorders, and few malignancies. ${ }^{7,8}$ However, an integrated safety summary from Phase I-III trials showed stable adverse events, with an incidence rate of 0.1-3.9 per 100 patient-years, and no new safety signals in patients who had used tofacitinib for up to 8.5 years. ${ }^{42}$ Moreover, a recent systematic review with network meta-analysis concluded that tofacitinib monotherapy had efficacy comparable to that of currently available biologics, as well as similar discontinuation rates due to adverse events. ${ }^{43}$ Current clinical evidence from trials and real-world observations support the safety of tofacitinib.

We acknowledge that this study had several limitations. First, we did not consider the costs of monitoring treatments or treatment of adverse events; this may have led to underestimation of overall healthcare expenditures for RA treatments. However, given that monitoring costs and numbers of adverse events from biologics and tofacitinib may be similar, ${ }^{43}$ the absolute changes in healthcare expenditures are not expected to differ from those we have described. Second, the expected tofacitinib dropout rate was established on the basis of landmark trials. Patient compliance and possible treatment switches in real-life clinical treatment settings were not analysed in this study. Thus, the results of this study should be interpreted cautiously with respect to the safety, efficacy, and adherence of tofacitinib 
and biologics. Third, we assumed constant costs for all treatments over the study period; in practice, these may be affected by the dynamic state of the market and a variety of possible interactions between costs and market share. Finally, structural and parametric uncertainties from the model were not tested comprehensively. Although we do not expect deviation from the base-case conclusion, future studies should assess model uncertainties while considering current clinical evidence with respect to the effectiveness and safety of novel DMARDs.

\section{Conclusion}

The introduction of tofacitinib to the Hospital Authority Formulary in Hong Kong for the treatment of patients with uncontrolled RA is expected to lower healthcare expenditures over the 5-year study period. The conclusion is robust in all scenario analyses with respect to uncertainties in drug costs, as well as in tofacitinib uptake and compliance.

\section{Author contributions}

All authors had full access to the data, contributed to the study, approved the final version for publication, and take responsibility for its accuracy and integrity.

Conception and design: X Li, EWY Chan.

Acquisition of data: X Li, KK Man.

Analysis or interpretation of data: X Li, KK Man, S Pathadka, EWY Chan.

Drafting of the manuscript: X Li.

Critical revision for important intellectual content: All authors.

Study supervision: ICK Wong, EWY Chan.

\section{Acknowledgements}

We acknowledge Mr Joseph E Blais and Dr In Hye Suh from the Department of Pharmacology and Pharmacy, The University of Hong Kong, for their critical review, thoughtful comments, and proofreading of the manuscript.

\section{Conflicts of interest}

EWY Chan has received funding from the Early Career Scheme and the General Research Fund from the Hong Kong Research Grants Council; the Health and Medical Research Fund, Food and Health Bureau, Hong Kong SAR Government; the Beat Drugs Fund from the Narcotics Division, Security Bureau; and the Young Scientist Fund, National Science Foundation Science Foundation of China, all unrelated to the current work. EWY Chan has also received research grants from Bayer, Bristol-Myers Squibb, Janssen Pharmaceutica, Pfizer, and Takeda, and honorarium from the Hong Kong Hospital Authority, all unrelated to the current work. ICK Wong received grants from the Hong Kong Research Grants Council, Innovative Medicines Initiative, Shire, Janssen Pharmaceutica, Eli Lilly, Pfizer, Bayer, and the European Union FP7 programme, all unrelated to the current work. ICK Wong was a member of the National Institute for Health and Clinical Excellence ADHD Guideline Group and the British Association for Psychopharmacology ADHD guideline group and acted as an advisor to Shire. $\mathrm{X}$ Li received a research grant from the Health and Medical Research Fund, Food and Health Bureau, Hong Kong SAR Government and consulting fees from Pfizer, unrelated to this work. KK Man received the CW Maplethorpe Fellowship and personal fees from IQVIA Holdings, Inc. (previously known as QuintilesIMS Holdings, Inc.), unrelated to this work. The other author(s) declare no conflicts of interest.

\section{Declaration}

Preliminary results from this study were presented (poster, title: Budget impact analysis of introducing tofacitinib for the treatment of patients with rheumatoid arthritis in Hong Kong) at ISPOR 7th Asia-Pacific Conference (Tokyo, Japan, 8-11 September 2018). The conference abstract was published in Value in Health (Volume 21, S80, DOI: https://doi. org/10.1016/j.jval.2018.07.599).

\section{Funding/support}

This work was supported by Pfizer Corporation Hong Kong Limited (grant No. RC170156). The funder had no role in the study design, data collection and analysis, preparation of the manuscript, or decision to publish.

\section{References}

1. World Health Organization. Chronic rheumatic conditions. Available from: http://www.who.int/chp/ topics/rheumatic/en/. Accessed 23 Jun 2017.

2. Singh JA, Saag KG, Bridges SL, et al. 2015 American College of Rheumatology Guideline for the Treatment of Rheumatoid Arthritis. Arthritis Rheumatol 2016;68:1-26.

3. Smolen JS, Landewé R, Bijlsma J, et al. EULAR recommendations for the management of rheumatoid arthritis with synthetic and biological disease-modifying antirheumatic drugs: 2016 update. Ann Rheum Dis 2017;76:960-77.

4. Curtis JR, Singh JA. Use of biologics in rheumatoid arthritis: current and emerging paradigms of care. Clin Ther 2011;33:679-707.

5. Mok CC, Tam LS, Chan TH, Lee GK, Li EK; Hong Kong Society of Rheumatology. Management of rheumatoid arthritis: consensus recommendations from the Hong Kong Society of Rheumatology. Clin Rheumatol 2011;30:303-12.

6. Ghoreschi K, Jesson MI, Li X, et al. Modulation of innate and adaptive immune responses by tofacitinib (CP690,550). J Immunol 2011;186:4234-43.

7. Lee EB, Fleischmann R, Hall S, et al. Tofacitinib versus methotrexate in rheumatoid arthritis. N Engl J Med 2014;370:2377-86.

8. Fleischmann R, Mysler E, Hall S, et al. Efficacy and safety of tofacitinib monotherapy, tofacitinib with methotrexate, and adalimumab with methotrexate in patients with rheumatoid arthritis (ORAL Strategy): a phase $3 \mathrm{~b} / 4$, double-blind, head-to-head, randomised controlled trial. Lancet 2017;390:457-68.

9. GoodPx. Tofacitinib. Available from: https://www.goodrx. com/tofacitinib. Accessed 14 Nov 2018.

10. Lee MY, Park SK, Park SY, et al. Cost-effectiveness of tofacitinib in the treatment of moderate to severe rheumatoid arthritis in South Korea. Clin Ther 2015;37:1662-76.e2.

11. Claxton L, Jenks M, Taylor $M$, et al. An economic evaluation of tofacitinib treatment in rheumatoid arthritis: 
modeling the cost of treatment strategies in the United States. J Manag Care Spec Pharm 2016;22:1088-102.

12. Claxton L, Taylor M, Gerber RA, et al. Modelling the cost-effectiveness of tofacitinib for the treatment of rheumatoid arthritis in the United States. Curr Med Res Opin 2018;34:1991-2000.

13. Mehta N, Schneider LK, McCardell E. Rheumatoid arthritis: selecting monotherapy versus combination therapy. J Clin Rheumatol 2017 Jan 18. Epub ahead of print.

14. Drug Office, Department of Health, Hong Kong SAR Government. Detail Information: XELJANZ TABLETS 5MG. Available from: https://www.drugoffice.gov.hk/eps/ drug/productDetail/en/consumer/76216. Accessed 19 Jun 2017.

15. Hong Kong Hospital Authority Drug Formulary. Available from: http://www.ha.org.hk/hadf/en-us/Updated-HADrug-Formulary/Drug-Formulary. Accessed 23 Oct 2017.

16. Lai EC, Man KK, Chaiyakunapruk N, et al. Brief report: databases in the Asia-Pacific region: the potential for a distributed network approach. Epidemiology 2015;26:81520.

17. Raman SR, Man KK, Bahmanyar S, et al. Trends in attention-deficit hyperactivity disorder medication use: a retrospective observational study using population-based databases. Lancet Psychiatry 2018;5:824-35.

18. Wong AY, Root A, Douglas IJ, et al. Cardiovascular outcomes associated with use of clarithromycin: population based study. BMJ 2016;352:h6926.

19. Cheung KS, Chan EW, Wong AY, Chen L, Wong IC, Leung WK. Long-term proton pump inhibitors and risk of gastric cancer development after treatment for Helicobacter pylori: a population-based study. Gut 2018;67:28-35.

20. Lau WC, Chan EW, Cheung CL, et al. Association between dabigatran vs warfarin and risk of osteoporotic fractures among patients with nonvalvular atrial fibrillation. JAMA 2017;317:1151-8.

21. Law SW, Lau WC, Wong IC, et al. Sex-based differences in outcomes of oral anticoagulation in patients with atrial fibrillation. J Am Coll Cardiol 2018;72:271-82.

22. Man KK, Chan EW, Ip P, et al. Prenatal antidepressant use and risk of attention-deficit/hyperactivity disorder in offspring: population based cohort study. BMJ 2017;357:j2350.

23. Chan EW, Lau WC, Leung WK, et al. Prevention of dabigatran-related gastrointestinal bleeding with gastroprotective agents: a population-based study. Gastroenterology 2015;149:586-95.e3.

24. Man KK, Coghill D, Chan EW, et al. Association of risk of suicide attempts with methylphenidate treatment. JAMA Psychiatry 2017;74:1048-55.

25. Singh JA, Hossain A, Tanjong Ghogomu E, et al. Biologics or tofacitinib for rheumatoid arthritis in incomplete responders to methotrexate or other traditional diseasemodifying anti-rheumatic drugs: a systematic review and network meta-analysis. Cochrane Database Syst Rev 2016;(5):CD012183.

26. National Institute for Health and Care Excellence. Guide to the methods of technology appraisal 2013. Apr 2013. Available from: https://www.nice.org.uk/article/pmg9/ chapter/Foreword. Accessed 7 Jul 2015.

27. Sanders GD, Neumann PJ, Basu A, et al. Recommendations for conduct, methodological practices, and reporting of costeffectiveness analyses: Second panel on cost-effectiveness in health and medicine. JAMA 2016;316:1093-103.

28. Mai Q, Aboagye-Sarfo P, Sanfilippo FM, Preen DB, Fatovich
DM. Predicting the number of emergency department presentations in Western Australia: a population-based time series analysis. Emerg Med Australas 2015;27:16-21.

29. Husereau D, Drummond M, Petrou S, et al. Consolidated Health Economic Evaluation Reporting Standards (CHEERS) statement. Value Health 2013;16:e1-5.

30. Fazal SA, Khan M, Nishi SE, et al. A clinical update and global economic burden of rheumatoid arthritis. Endocr Metab Immune Disord Drug Targets 2018;18:98-109.

31. Hospital Authority, Hong Kong SAR Government. Drug review and selection mechanism. Available from: http:// ha.org.hk/visitor/ha_visitor_text_index.asp?Content_I $\mathrm{D}=208041 \&$ Lang $=$ ENG\&Dimension $=100 \&$ Parent ID=206049\&Ver=TEXT. Accessed 29 Mar 2017.

32. National Institute for Health and Care Excellence. Budget impact test. Available from: https://www.nice.org.uk/ about/what-we-do/our-programmes/nice-guidance/ nice-technology-appraisal-guidance/budget-impact-test. Accessed 19 Jun 2017.

33. Scott AM. Health technology assessment in Australia: a role for clinical registries? Aust Health Rev 2017;41:19-25.

34. Canadian Agency for Drugs and Technologies in Health. About the health technology assessment service. Available from: https://www.cadth.ca/about-cadth/what-we-do/ products-services/hta. Accessed 19 Jun 2017.

35. Wong CK, Wu O, Cheung BM. Towards a transparent, credible, evidence-based decision-making process of new drug listing on the Hong Kong Hospital Authority Drug Formulary: challenges and suggestions. Appl Health Econ Health Policy 2018;16:5-14.

36. Goddard M. Competition in healthcare: good, bad or ugly? Int J Health Policy Manag 2015;4:567-9.

37. Genovese MC, van Vollenhoven RF, Wilkinson B, et al. Switching from adalimumab to tofacitinib in the treatment of patients with rheumatoid arthritis. Arthritis Res Ther 2016;18:145.

38. Vieira MC, Zwillich SH, Jansen JP, Smiechowski B, Spurden D, Wallenstein GV. Tofacitinib versus biologic treatments in patients with active rheumatoid arthritis who have had an inadequate response to tumor necrosis factor inhibitors: results from a network meta-analysis. Clin Ther 2016;38:2628-41.e5.

39. Alten R, Krüger K, Rellecke J, et al. Examining patient preferences in the treatment of rheumatoid arthritis using a discrete-choice approach. Patient Prefer Adherence 2016;10:2217-28.

40. Li Z, An Y, Su H, et al. Tofacitinib with conventional synthetic disease-modifying antirheumatic drugs in Chinese patients with rheumatoid arthritis: Patientreported outcomes from a Phase 3 randomized controlled trial. Int J Rheum Dis 2018;21:402-14.

41. Augustovski F, Beratarrechea A, Irazola V, et al. Patient preferences for biologic agents in rheumatoid arthritis: a discrete-choice experiment. Value Health 2013;16:385-93.

42. Cohen SB, Tanaka Y, Mariette X, et al. Long-term safety of tofacitinib for the treatment of rheumatoid arthritis up to 8.5 years: integrated analysis of data from the global clinical trials. Ann Rheum Dis 2017;76:1253-62.

43. Bergrath E, Gerber RA, Gruben D, Lukic T, Makin C, Wallenstein G. Tofacitinib versus biologic treatments in moderate-to-severe rheumatoid arthritis patients who have had an inadequate response to nonbiologic DMARDs: systematic literature review and network meta-analysis. Int J Rheumatol 2017;2017:8417249. 